\title{
Causes of Vocational College Students' Reticence in EFL Classrooms of Mainland China - based on Panxi Vocational College
}

\author{
Jun Fu* \\ Panzhihua Panxi Vocational College, Panzhihua 617200, Sichuan Province, China \\ *Corresponding author: Jun Fu, June.Fu@hotmail.com
}

\begin{abstract}
This article reports on a study of students' reticence in English as a Foreign Language (EFL) classrooms in Panxi Vocational College in Sichuan Province of Mainland China. Forty-one students answered a 28-item questionnaire. The students' reticence levels, general tendency of unwillingness-to-speak, and their learning behaviors were identified. Individual and social factors contributing to the reticence phenomenon in the vocational college's EFL classrooms were also determined. The results suggested that culture have strong influences on Chinese vocational college students' reticence. However, their habitual classroom behaviors that have been established for a long time should be taken into account in regard to their reticence.
\end{abstract}

Keywords: Students' reticence; Vocational college EFL classroom; Culture; Learning style

Publication date: June 2021; Online publication: June 30, 2021

\section{Background}

Under the circumstance that Chinese government attaches great importance to vocational education, higher vocational education is rapidly developing. Vocational college students need to be proficient and master the English language to face future challenges. However, the English-language teachings in vocational colleges are not dynamic in which students are quiet and lack enthusiasm during EFL classes. This study is mainly aimed at the phenomenon of vocational college students' reticence in order to understand the causes relating to individual and social factors.

\section{Causes of students' reticence}

This section will focus on factors contributing to students' reticence in the Chinese vocational college. The reasons for students' reticence are clearly shown in Figure 1. 


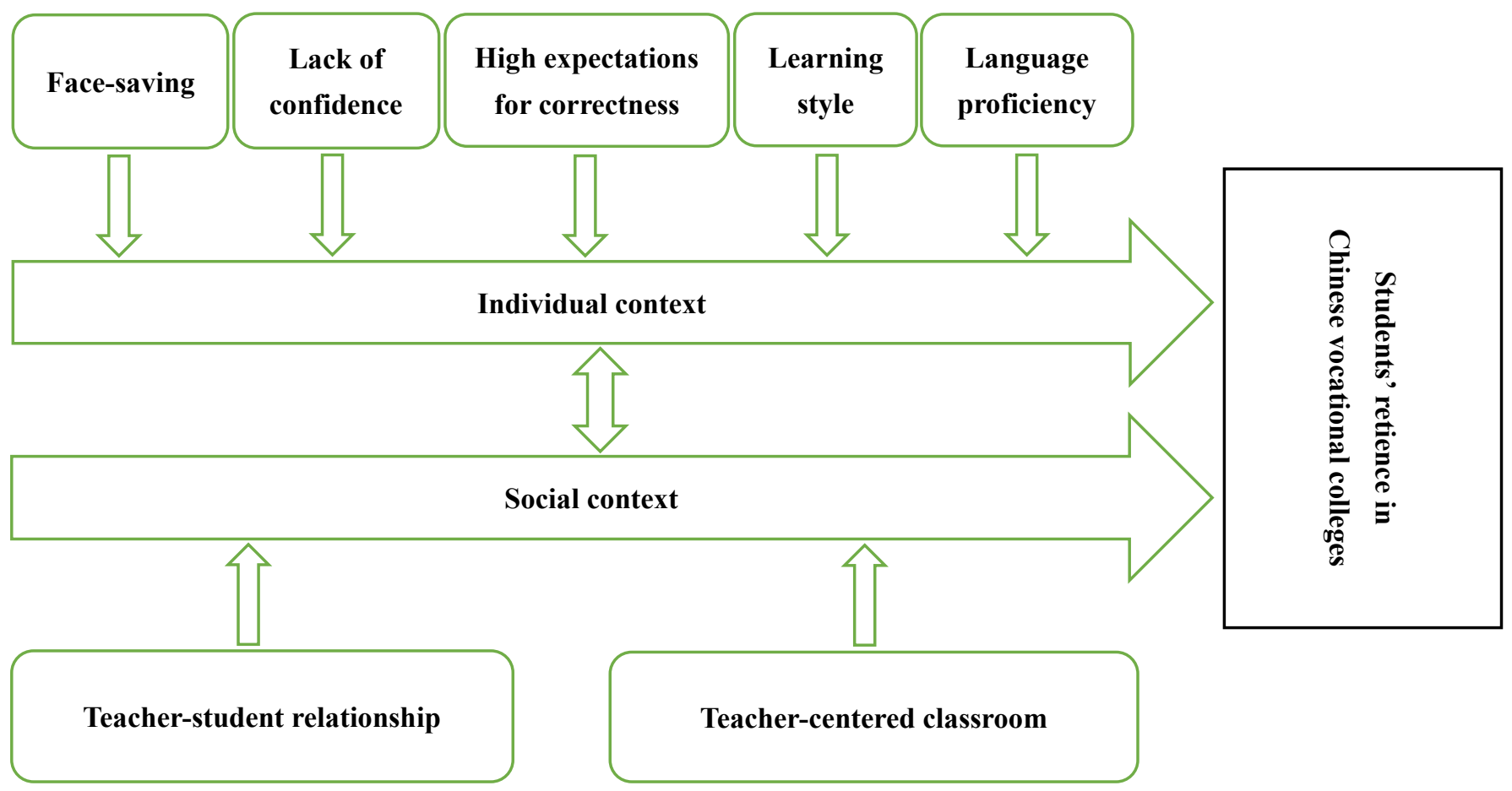

Figure 1. Factors contributing to students' reticence in EFL classrooms of the Chinese vocational college

\subsection{Social context}

Two factors in the social context are identified in this study which are teacher-student relationship and traditional teacher-centered classroom.

\subsubsection{Teacher-student relationship}

As Liu \& Littlewood said "Confucian values have become a convenient explanation for any observed or actual behavior trait."[1] In Confucianism, teacher-student relationship does not encourage students to question teachers in class. ${ }^{[2]}$ In China, teachers have the role of cultivating the souls of students who are conceptualized as the future of the country. Therefore, teachers have high social status in the Chinese culture and have gained students' respect not only to impart knowledge based on the subjects taught but also, play a primary role as moral cultivators. They are conceptualized as the authoritative figure and are responsible for initiating interactions during classes. In such a hierarchical relationship between teachers and students, students expect their teachers to provide knowledge and information as they view teachers as a source of wisdom. ${ }^{[3]}$

\subsubsection{Teacher-centered classroom}

A few researchers have claimed that the absence of opportunities for interactions is a result of excessive control from the teachers. ${ }^{[4]}$ According to Cullen, "Good' teacher talk means 'little' teacher talk." ${ }^{[5]} \mathrm{He}$ believed that if teachers' talk time (TTT) was considerably long, it would deprive students of opportunities to speak. This study found that the vocational college's English-language classrooms were based on teacher-centered approach which is normally displayed as teachers imparting knowledge via using PowerPoint slides or the blackboard while students listened and jot down notes.

In addition to that, teachers' low tolerance for silence is expressed while waiting for students to answer their questions. The time given for students to prepare prior answering the questions is too short. Hence, the low tolerance for silence results in teachers either answering the questions themselves or in designating 
a particular student to respond via individual nomination. Mehan suggested three basic turn-regulating procedures in regard to classroom interactions which are individual nominations (i.e., teachers verbally or nonverbally designate a specific student to reply), invitations to bid (i.e., teachers requesting students to indicate their willingness to reply by some means such as raising hands or maintaining eye contact), and invitations to reply (i.e., teachers' open invitation for any students to reply directly). ${ }^{[6]}$

\subsection{Individual context}

There are five factors in terms of individual context that are identified based on the data analysis of this study. They are face-saving, lack of confidence, high expectations for correctness, learning style, and language proficiency.

\subsubsection{Face-saving}

Most respondents usually respond to their teachers with a 'yes' or nod their heads to confirm their understanding. They would also turn to their classmates for clarification. This phenomenon has been discussed by Watson and Liu. ${ }^{[7,8]}$ This is because students would feel stupid to admit that they do not know what they are supposed to be aware of. Their personal image is important in this collectivist culture which is an influence of Confucius who emphasized on harmony and face-saving. It was mentioned that, "A failure of 'face-protecting' would lead to a loss of self-esteem and reputation."[9] Face-saving would hinder students of speaking opportunities in classrooms. This is supported by Jackson who claimed that the strong preference of Chinese students to remain silent in classes while quietly discussing with their classmates outside classes is influenced by Confucianism. ${ }^{[10]}$

\subsubsection{Lack of confidence}

Only 5\% of the participating students agreed with "I feel confident when I speak English in class." Students have always been consciously or unconsciously competing with their classmates. Their actual performance may be good compared to their classmates but they usually evaluate themselves negatively. Some even think that they need to speak perfectly in order to be deemed competent as a person. ${ }^{[1]}$ Their self-perception as incompetent speakers prevents them from actively participating in classroom activities.

\subsubsection{High expectations for correctness}

Students often feel frightened at the idea of making mistakes and receiving negative evaluations from their peers. About $81 \%$ of the participants were worried about making mistakes in this study. Hence, they might have avoided that by being reticent while thinking that they would be able to practice the English language outside classrooms by themselves. In regard to high expectations for correctness, students tend to be slower in their responses which would lead to silent atmospheres in classrooms. This 'slowness' is understood as preparations or processing questions prior answering by which they whisper among themselves to avoid mistakes or translating sentences into their mother language, organizing their thoughts, and then only word their thoughts in English; hence, delaying their responses to the teachers.

Making mistakes is unavoidable in the language learning process. If students are willing to take risks to speak, they will then have greater exposure to that particular language. Otherwise, the fear of making mistakes may prevent students from speaking in class. This is supported by Tudor who suggested that risktaking can foster language use and is likely to expand the learners' exploration of the target language; thus, increasing potentially productive learning opportunities. ${ }^{[12]}$ 


\subsubsection{Learning style}

Under the influence of "teachers as moral cultivators" in the Chinese education system, students are not only expected to pay respect to teachers during classes but also, to the materials that the teachers use for teaching. Many Chinese idioms reveal the attitudes of Chinese learners toward books. For example, Kai Juan You Yi which implies the benefit of books and Shu Zhong Zi You Huang Jin Wu which expresses that "books are valuable."

In China, students are expected to memorize the materials from textbooks. Therefore, in this study, only $12.5 \%$ participants disagreed with "I prefer using a textbook than talking in class." It has been discussed by Kennedy that books are thought of as an embodiment of knowledge, wisdom, and truth. ${ }^{[11]}$ Since students in China learn Chinese as their mother language, it is habitual for them to memorize different characters that they encounter. Therefore, Kennedy believes that students transfer their Chinese learning habits to the learning of foreign languages. ${ }^{[13]}$ In English-language classes, students are accustomed to keep quiet, take notes, and carefully listen to their teachers without interrupting as a sign of respect to their teachers who are deemed as a source of wisdom. Their learning behaviors prohibit them to take up communicative roles in English-language classes.

\subsubsection{Language proficiency}

Students' reticence due to poor language proficiency has been discussed by many researchers. ${ }^{[1,13-15]}$ Students find it difficult to understand what teachers say during classes; thus, they are unable to respond to questions or sometimes, even understand them in addition to the difficulty in expressing themselves well due to poor language proficiency. Keeping quiet and avoiding eye contact are strategies used in classrooms when students are dealing with confusion. Therefore, teachers suppose that the students are not ready to answer the questions. One very possible phenomenon in group discussions is that when students are asked to engage in discussions on a given topic, students' would prefer to use Mandarin in view of poor English speaking skills.

\section{Conclusion}

This study intended to find out the causes of vocational college students' reticence in mainland China's EFL classrooms. Questionnaires were distributed to 41 students and the results identified the students' reticence level, general tendency of unwillingness-to-speak, and their learning behaviors. The size and background of samples are significant limitations. The results from one vocational college in a city does not proportionally represent the whole country. Especially in China, there are significant diversities between the northern and southern regions, big and small cities, as well as urban and rural areas.

In conclusion, although this study has limitations, its significance of English-language teachings in Chinese vocational colleges should not be neglected. Directions for future research include studies with more participants from different backgrounds in terms of college, area, and age as well as using technology equipment in data collections. Last but not the least, researchers should also carefully and widely consider the factors that contribute to students' reticence in their future research.

\section{Disclosure statement}

The author declares no conflict of interest. 


\section{References}

[1] Littlewood W, Liu NF, 1996, Hong Kong students and their English, Macmillan, Hong Kong.

[2] Scollon R, Scollon S, 1995, Intercultural communication, Blackwell, Oxford.

[3] Woodrow D, Sham S, 2001, Chinese pupils and their learning preferences in race ethnicity and education., 4(4): 377-94.

[4] Cortazzi M, Jin L, 1996, Cultures of learning: language classroom in China, Cambridge University Press, Cambridge.

[5] Cullen R, 1998, Teacher talk and the classroom context. ELT Journal, 53(3): 179-87.

[6] Mehan H, 1979, Learning lessons: social organization in the classroom, Cambridge University Press, Cambridge.

[7] Watson DI, 1999, 'Loss of face' in Australian classrooms. Teaching in Higher Education, 4(3): 355-62.

[8] Liu M, 2006, Anxiety in Chinese EFL students at different proficiency levels. System, 34: 301-16.

[9] Tsou W, 2005, Improving speaking skills through instruction in oral classroom participation. Foreign Language Annals, 38(1): 46-55.

[10] Jackson J, 2003, Case-based learning and reticence in a bilingual context: perceptions of business students in Hong Kong. System, 31: 457-69.

[11] Kennedy P, 2002, Learning cultures and learning styles: myth-understanding about adult (Hong Kong) Chinese learners. International Journal of Lifelong Education, 21(5): 430-45.

[12] Tudor I, 1996, Language-centeredness as language education, Cambridge University Press, Cambridge.

[13] Tsui ABM, 1996, Reticence and anxiety in second language learning, Cambridge University Press, Cambridge.

[14] Cheng X, 2000, Asian students' reticence revisited. System, 28: 435-46.

[15] Xia SH, 2009, Are they ready to participate? East Asian student acquisition of verbal participation in American classrooms. Applied Linguistics, 17(2): 137-57.

[16] Flowerdew J, Miller L, 1995, On the notion of culture in 12 lectures. TESOL Quarterly, 29(2): 345-73.

[17] Liu M, Jackson J, 2009, Reticence in Chinese EFL students at varied proficiency levels. TESL Canada Journal, 26(2): 65-81.

[18] Peng JE, 2007, Willingness to communicate in the Chinese EFL classroom: A cultural perspective. Perspectives and Standards, :250-69.

[19] Xie XY, 2010, Why are students quiet? looking at the Chinese context and beyond. ELT Journal, 60(1): $10-20$.

[20] Zhang XQ, Head K, 2010, Dealing with learner reticence in the speaking class. ELT Journal, 64(1): 19. 